\title{
Rosemary Ellis' Views on the Substantive Structure of Nursing
}

\author{
Donna L. Algase, Ann F. Whall
}

According to the late Rosemary Ellis, the most pressing priority of nursing scholars is to explicate the substantive structure of our discipline. Drawing largely from her unpublished work, this paper summarizes the views of Ellis on the nature of nursing's substantive structure and raises implications for the development of nursing theory.

[Keywords: epistemology, theory construction]

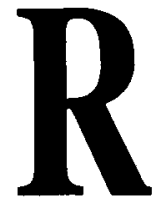

osemary Ellis' writings on theoretical issues in nursing have had substantial impact on the field (Pressler \& Fitzpatrick, 1988). Unfortunately, Ellis never published in its entirety her view of nursing as a discipline. However, by her teaching and interactions with influential thinkers, Ellis shaped the way numerous scholars regard nursing as discipline and profession. As two persons so influenced, we offer this discussion of her positions, supplementing published ideas with her unpublished thoughts, as recorded by one author during a doctoral level theory course offered by Ellis at Case Western Reserve University in the summer of 1984, and as recalled by both authors from numerous discussions with Ellis in and aside from meetings of the Nursing Theory Think Tank. Sadly, Ellis is no longer here to clarify our understandings of her views. Such dialogue now depends on interaction among her former students and colleagues. We rely upon these nurses to question and validate our depiction of her thoughts.

In explicating the nature of nursing as a discipline, Ellis was guided by two key ideas: disciplinary matrix and disciplinary output. Disciplinary matrix implied interaction or interrelatedness among elements of the discipline's structure (Ellis, 1984b). To Ellis (1984c), reference to a structure or a "body of knowledge" in nursing was metaphorical or connotative, not literal or denotative. Structure implied cohesion, order, sense or logic in the way nurse scholars consider and produce meanings. Consistent with Donaldson and Crowley (1977), Ellis drew from works by educators Foshay (1961) and Schwab (1962) to portray disciplinary matrix in terms of two broad substructures: substantive and syntactical. Disciplinary output was examined in terms of Phenix's (1964) realms of meaning.

To Ellis, explication of the substantive structure of nursing was plainly the most pressing priority of our discipline. She believed that, until we are clear about what we are about, debates on all else within the discipline were premature (1984a). Thus, this paper focuses on Ellis' view of the substantive structure of nursing and, as such, offers only partial understanding of the discipline of nursing as Ellis knew it. The breadth and depth of her views on the whole of nursing as a discipline are too comprehensive to treat in a single paper.

\section{Relationship of Disciplinary to Professional Knowledge}

Ellis' grasp of the discipline of nursing and relationship of its various elements and substructures was predicated on a particular stance regarding the linking of a professional discipline to its related profession. This stance warrants discussion for two reasons: first, it is distinct from the position of many contemporary nurse scholars and, second, if held by other such scholars, this stance has not been clearly explicated elsewhere in the literature.

In common with her contemporaries, Ellis held that the profession and discipline of nursing were linked through a shared interest in and language for the phenomena of nursing practice (Ellis, 1984d). Accordingly, practice serves as the proper referent or raison d'etre for nursing as a discipline. As nurses first, scholars of the discipline understand the good or beneficence that the practice of nursing aims to contribute to society (1984b). Further, scholars and practitioners of nursing share a value structure, particularly in our regard for persons, that permeates both our science and our practice.

Somewhat distinct from her contemporaries, Ellis believed that disciplinary (or uniquely nursing) knowledge was but a part

Donna L. Algase, RN, PhD, Rho, Zeta Theta, is Assistant Professor of Gerontological Nursing and Assistant Research Scientist; Ann F. Whall, RN, PhD, FAAN, Rho, is Professor and Specialty Head of Gerontological Nursing, both at the School of Nursing, University of Michigan. Correspondence to School of Nursing, University of Michigan, $400 \mathrm{~N}$. Ingalls, Ann Arbor, MI 48109-0482.

Accepted for publication February 17, 1992. 
of that needed and possessed by practicing professionals (1984, f). Thus, the substantive structure of the discipline need not account for, encompass, nor "reformulate" to a nursing view all knowledge needed or used in practice. When studied or applied in the context of practice, for example, a theory of cell physiology is still physiology: applied physiology, perhaps, but not nursing or nursing physiology. Rather, the substantive structure of the nursing discipline pertains when the phenomenon or object of study is selected, queried and approached from a concern for the goals of nursing as a practice. In other words, the thing studied, the questions raised about it, and the method or approach used to investigate it are those that only nurses, by virtue of their grounding in nursing's beneficence and values, would think to employ.

Conversely, not all studies conceived and conducted by nurses contribute to the discipline of nursing. Because nurses apply knowledge from many disciplines in the course of nursing practice, a case for the relevance of such knowledge to our practice can often be made. However, nurse scholars employing, in toto, the substantive structure of another discipline to the study of phenomena encountered in nursing practice cannot necessarily claim that the products of their studies fit within the discipline of nursing. In other words, a nurse sociologist, for example, may at times generate sociological knowledge about a phenomenon, such as family, common to nursing and sociology. In this situation, the distinction (or overlap, if possible) between what is nursing knowledge and what is sociological knowledge rests in the relevance of the knowledge to the purposes or beneficence of nursing practice and in the congruence between values and methods in nursing and sociology.

\section{The Substantive Structure of Nursing as a Discipline}

Ellis viewed the substantive structure of disciplines as conceptual in nature $(1984 \mathrm{~g})$. Accordingly, the substantive structure is that which members of a discipline seek truth about and the terms within which such truth is framed. The substantive structure, or subject matter of a discipline, is represented in its perspective, its domain or field of phenomena, and its persistent or stubborn questions. Ellis believed it was the substantive structure in toto, rather than any single element of it, that constituted real differences between disciplines.

\section{Perspective}

Ellis understood perspective as the prevailing view or general stance held by most scholars, in apprehending or perceiving phenomena within their domain $(1984 a ; 1984 c)$. A perspective is constituted of the most basic or primitive set of organizing concepts common to scholars of a field. The meanings and relationships of basic concepts constituting a discipline's perspective bind, cast or focus in a certain way the phenomena pertinent to it. Thus, inherent in perspective is a set of assumptions regarding the nature of the world and an emphasis on or preference for some values over others.

Ellis offered some insights on nursing's perspective as she saw it. For example, she suggested the concepts of disease and lifestyle as intriguing to both medicine and nursing (1982; 1984a). However, she thought medicine's likely concern was to know how disease might manifest, given various life styles, whereas nursing's likely interest was to know when and how to preserve or modify life style, in light of what is known about disease. In apprehending or perceiving phenomena, Ellis thought medicine had a sequential (from subjective to objective) perspective and nursing a simultaneous (holistic) one. Ellis (1982; Pressler \& Fitzpatrick, 1988) also thought that nursing's perspective encompassed health promotion. Ellis upheld the commonly accepted metaparadigm concepts of person, health, environment (sometimes subsumed under person), and nurse (the verb) as roughly binding our perspective, but believed that we lack consensus on defining these abstractions and in linking them together (1984c). As evidence, she cited diversity in definitions or meanings for these concepts in nursing "conceptualizations" or models such as Orem (1979), Roy (1976) and Rogers (1970). However, Ellis (1984g) did not advocate a unifying conceptual model and held that a plurality served to highlight or emphasize different central phenomena, but not to affect our overall perspective.

Ellis urged scholars to work at less abstract levels in further developing or making apparent the cohesion within our perspective. As one possibility, she suggested strategies such as examining tacit or implied meanings of terms used to refer to persons receiving nursing care to make our view on person and its relationship to other basic concepts more explicit (Ellis 1984b). For example, terms such as newborns, adolescents, adults or elderly suggested to Ellis that nursing's perspective on persons encompassed a developmental view and implied relationships between development and health; whereas, the terms retardates, the unconscious, the vegetative or the demented suggested a narrower focus on levels of awareness or capacity for assuming self responsibility in the presence of altered developmental or health states. These two views could result in different professional aims: nursing beneficence as enhancing abilities versus solving problems. Ellis recommended further study of what constituted "patientness" to advance our understanding of nursing's perspective. Similarly, she believed that further inquiry into the nature of health, environment and nursing were needed.

\section{Domain}

Ellis (1984b) equated the notion of domain with the field or array of phenomena of interest to a discipline's scholars; domain connoted scope (Ellis, 1984h). Phenomena had an "out there" quality; that is, they existed in reality, but their meanings were created or generated (Ellis, 1984i). The domains of various disciplines were thought to be overlapping, at least in part, and a domain in and of itself, did not distinguish one discipline from another for Ellis. What varied substantively among disciplines concerned with the same phenomena was the conceptual structure or meaning applied to such phenomena and their interrelationships. Conversely, Ellis saw that disciplines overlapped in their use of terms and concepts. Though a term may be common to two disciplines, each discipline's meaning and protocol data for it may differ. 
To Ellis, nursing's domain was constituted of phenomena encountered in producing the good that is the aim of nursing practice. Ellis (1984j) claimed that no accepted "list of phenomena" appropriate to the discipline of nursing existed, but cited nursing diagnoses and examples listed in Nursing-A Social Policy Statement (American Nurses' Association, 1980, p. 10) as imperfect, but appropriate, points of departure.

Because practice is the referent for circumscribing nursing's domain and practice evolves within a social contract and context, domain is dynamic. Since nursing curricula encompass the knowledge important to practice, Ellis thought that an understanding of various ways curricula had been structured over time could point up the structure or organization inherent in nursing's domain. But, from her study of the history of nursing curricula, as reflected in the works of Stevens (1971) and Longway (1972), she concluded that clinical specialization in nursing practice had negatively affected organization of knowledge in nursing (Ellis, 1984k). Largely following the lines of medical specialization, such divisions had retarded development of a unified perspective and a general consensus regarding phenomena common to nursing practice across medical specialties. Such groupings of patients were more a matter of practicality than a structure for or guide to developing knowledge for Ellis (1984g).

One other way to grasp Ellis' meaning of less abstract concepts and relevant clinical phenomena is to review examples she used herself to illustrate her meanings. In published works, Ellis (1968; 1969) cited dependence, incontinence, post-operative ambulation, feelings of helplessness, visual development of the infant, patient's naming of pathology or body parts altered by pathology, patients' use of humor, appetite, back care, nurses' practice of encouraging verbalization about illness and tender loving care as illustrations of phenomena and concepts within the domain of nursing. Her research on sensory deprivation (Jackson $\&$ Ellis, 1971) is a further reflection of her views. Such examples represent a cross-section of patient states and behaviors, as well as nursing actions or interventions.

\section{Stubborn Questions}

According to Ellis (1984a), a third component of a discipline's substantive structure was its pressing or stubborn questions. To Ellis, such questions were closely entwined with perspective and domain. In other words, because a discipline's scholars viewed certain phenomena from a particular stance, they would "naturally" ask a distinctive type of question. For example, anatomists, concerned with form, ask questions concerning bodily structure, while physiologists, concerned with function, inquire into fundamental bodily processes.

Ellis (1984a) believed that nursing questions were the least clearly explicated aspect of the discipline's substantive structure and that debates over syntax or methods were premature until we deliberated our fundamental questions. To arrive at a clearer sense of what nursing seeks to know, she urged scholars to examine questions in nursing studies and extract underlying themes from them.

Ellis (1984a) suggested that nursing questions were concerned with the nature of human states and behaviors in regard to health and with knowing how to effect optimal states of health through some processes called nursing. Further, she speculated that nursing questions may be more teleological, or concerned with consequences, than etiological, or concerned with causes (Ellis, $1982 ; 1984 \mathrm{a} ; 1984 \mathrm{~g})$.

\section{Implications for Theory Development}

Ellis suggested that an understanding of nursing's substantive structure is fundamental, and probably of primary importance, to further development of the discipline. Furthermore, her work implies that our current understanding of this structure is at an embryonic level. Ellis made several direct suggestions for further clarifying our substantive structure, but these strategies are more within the sphere of metatheoretical or philosophical inquiry than of theory development for nursing practice.

Nonetheless, the needs of patients for informed nursing care persist and theory to guide professional nursing practice is urgently needed. So, however inchoate our ability to articulate the substantive structure of nursing, efforts to generate theory thought to fall within its limits should continue. Given the needs of the profession, then, what are the implications for theory development that can be gleaned from Ellis' explication of nursing's substantive structure? First, of greatest importance are efforts to understand common everyday phenomena exhibited by persons under the care of nurses. In particular, the highest priority should be placed upon phenomena entrusted solely or primarily to the nurse for resolution, management, or care. These, it could be assumed from Ellis' views, would most clearly illustrate, reflect, or somehow characterize, the beneficence of nursing and would, therefore, clearly fall within the purview of the discipline.

Second, the puzzlement or perplexity such phenomena create for the nurse should be carefully pondered. Pressed as practitioners are for proven solutions, scholars should resist the temptation to test alternatives prematurely. Rather, we should carefully consider what it is about a phenomenon that troubles the nurse. In general, what does a phenomenon mean for health? And, how do person and environment come together to yield this phenomenon? As a particular example, is wandering behavior of cognitively-impaired elderly healthful or harmful? And, what personal and environmental factors and conditions explain or contribute to its occurrence? Once understood, efforts at alleviating, remediating or otherwise nursing the problem can be more appropriately selected for systematic investigation.

Finally, efforts at theory development must be evaluated for congruence with a nursing value system and view. In regard to substantive structure, the concepts employed and the meaning imparted through theory must not violate a respect for the autonomy and uniqueness of persons and a regard for their holistic nature.

\section{Epilogue}

Rosemary Ellis was indeed a visionary and gifted nurse scholar. No doubt, her thoughts on the discipline of nursing will engender study and debate having far reaching consequences for 
this field of knowledge. Though her influence to date has been felt primarily at the metatheoretical level of knowledge development in nursing, her ideas have direct application to scholars working at less abstract levels. Dr. Ellis' thoughts on the substantive structure of the discipline of nursing provide direction for scholars in selecting and questioning the phenomena of nursing practice. $[$ [ET]

\section{References}

American Nurses' Association, (1980). Nursing - A social policy statement. Kansas City, MO: Author.

Donaldson, S.K. \& Crowley, D.M. (1977). Discipline of nursing: Structure and relationships to practice. Communicating Nursing Research, 10, 1-22.

Ellis, R. (1968). Characteristics of significant theories. Nursing Research, 17, 217-222.

Ellis, R. (1969). The practitioner as theorist. American Journal of Nursing, 69, 1434-1438.

Ellis, R. (1982). Conceptual issues in nursing. Nursing Outlook, 30, 406-410.

Ellis, R. (1984a). Personal communication, class notes, July 6, 1984. Case Western Reserve University, Cleveland, $\mathrm{OH}$.

Ellis, R. (1984b). Personal communication, class notes, July 11, 1984. Case Western Reserve University, Cleveland, $\mathrm{OH}$.

Ellis, R. (1984c). Personal communication, class notes, July 9, 1984. Case Western Reserve University, Cleveland, $\mathrm{OH}$.

Ellis, R. (1984d). Personal communication, class notes, June 4, 1984. Case Western Reserve University, Cleveland, $\mathrm{OH}$.

Ellis, R. (1984e). Personal communication, class notes, June 29, 1984. Case Western Reserve University, Cleveland, $\mathrm{OH}$
Ellis, R. (1984f). Personal communication, class notes, July 16, 1984. Case Western Reserve University, Cleveland, $\mathrm{OH}$.

Ellis, R. (1984g). Personal communication, class notes, July 13, 1984. Case Western Reserve University, Cleveland, $\mathrm{OH}$.

Ellis, R. (1984h). Personal communication, class notes, June 18, 1984. Case Westem Reserve University, Cleveland, $\mathrm{OH}$.

Ellis, R. (1984i). Personal communication, class notes, June 8, 1984. Case Western Reserve University, Cleveland, $\mathrm{OH}$.

Ellis, R. (1984j). Personal communication, class notes, June 13, 1984. Case Western Reserve University, Cleveland, $\mathrm{OH}$.

Ellis, R. (1984k). Personal communication. Case Western Reserve University, Cleveland, $\mathrm{OH}$.

Foshay,A.W. (1961). Knowledge and the structure of the disciplines. Unpublished paper, University of Wisconsin.

Jackson, C.W. \& Ellis, R. (1971). Sensory deprivation as a field of study. Nursing Research, 20, 46-54.

Longway, I.M. (1972). Curriculum concepts: An historical analysis. Nursing Outlook, 20, 116-120.

Orem, D. (Ed.). (1979). Concept formalization in nursing (2nd ed.). Boston: Little, Brown.

Phenix, P.H. (1964). Realms of meaning. New York: McGraw-Hill.

Pressler, J.L. \& Fitzpatrick, J.J. (1988). Contributions of Rosemary Ellis to knowledge development for nursing. Image, 20, 28-30.

Rogers, M.E. (1970). An introduction to the theoretical basis of nursing. Philadelphia: F.A. Davis Co.

Roy, S.C. (1976). Introduction to nursing: An adaptation model. Englewood Cliffs, NJ: Prentice-Hall, Inc

Schwab,JJ. (1962). The concept of the structure of a discipline. The Educational Record, 43, 197-205.

Stevens, B. (1971). Analysis of the structural forms used in nursing curricula. Nursing Research, 20, 399-397.

\section{UNIVERSITY OF ROCHESTER SCHOOL OF NURSING}

\author{
- Primary Care (Family NP) Adult - \\ - Acute/Chronic Hoalth • \\ - Hoalth Systems/Haalth Services.
}

The School of Nursing at the University of Rochester seeks faculty for full-time academic tenure track positions in Primary Care (Family NP) Adult, Acute/Chronic Health, Hoalth Systema/Health Services. Master's in Nursing specialty area and Doctorate in Nursing or related field are required. Responsibilities include participation in unification model of nursing scholarship involving teaching, practice, and research. The School of Nursing is part of the University of Rochester Medical Center as well as the larger University of Rochester. NLN-accredited programs are offered at the B.S., M.S., and Ph.D. levels. Salary and rank commensurate with experience and qualifications. Send resume and references to Dean Sheila Ryan, University of Rochester School of Nursing, 601 Elmwood Avenue, Box 703, Rochester, New York 14642. Phone: (716) 2752372. The University of Rochester is an equal opportunity employer.

\section{UNIVERSITY OF PITTSBURGH SEHOOL OF MURSIISG}

The University of Pittsburgh School of Nursing invites applications for Nursing faculty positions in undergraduate and graduate programs in the specialty areas of: pediatrics, maternity, community health, medical-surgical, gerontology, primary care nurse practitioners, and critical care. Master's degree in the specialty required and doctorate preferred. RankJsalary commensurate with qualifications.

The University of Pittsburgh offers more than 400 degree programs to an enrollment of more than 34,000 students accounting for 6.1 percent of all students enrolled in institutions of higher education in Pennsylvania. Pitt is one of the 58 members of the Association of American Universities (AAU) that collectively perform a major share of basic research in the United States and Canada.

The School of Nursing has baccalaureate, master's and doctoral programs. It offers strong support for research and houses its own Center for Nursing Research which provides consultation to faculty on the development of research efforts including proposals. The School is affiliated with an excellent health center and community agencies.

Please send letter of application and resume to: Dr. Patricia Geary, Associate Dean, Academic and Clinical Affairs, University of Pittsburgh School of Nursing, 350 Victoria Building, Pittsburgh, Pennsylvania 15261. An EO/AA employer. 